\title{
The Relationship between Academic Procrastination and Future- Orientation: an Investigation among a Mid-sized International School in China
}

\author{
Yi-Ran SHI ${ }^{1, a}$ \\ Keystone Academy, Beijing, China, 101318 \\ email: yiran0811@outlook.com
}

Keywords: Procrastination, Future-orientation, High-school students.

\begin{abstract}
As one proceeds through school, the responsibility of controlling his or her academic behavior shift significantly from teachers and parent-centered to self-centered. Study and programs were established to help college students ease this process (example studies need to be cited here). However, often do they neglect the origin of these academic habits are shaped and formed in secondary education period (citation needed). This study examines the potential cause of academic procrastination behaviors among Chinese high school students ( $\mathrm{N}$ $=150$ ) studying in an international school.
\end{abstract}

\section{Introduction}

The term Procrastination means the tendency to delay initiation or completion of important tasks to the point of discomfort [1], which is often viewed as a kind of regulation failure. In the same vein, academic procrastination is the irrational delay in executing academic assignments required for students (e.g., problem-solving practice, reading, exam revision) [2]. Although psychologists are trying to explain the reason behind procrastination, the causes of procrastination still did not reach a universal conclusion[3]. Specifically, academic procrastination has significant ramification for students at all age levels, includes a strong negative indicator of grade point average [4], and a positive indicator of stress [5]. There is a growing attention in procrastination research. Analysis of the PsycINFO database reported that there had been 117 articles about procrastination published after 2000 (there are only 38 theses published in the previous seven years [6]. The current study explores the motivators correlates with those for whom uncompleted task has a great impact now and future: post-secondary procrastinators.

Practical literature and academic researchers have associated negative student performance with Procrastination behavior. Procrastination refer to the intentional postpone of a planed task, in spite of being aware of adverse outcomes [7]. While empirical and theoretical argument of procrastination are less firm compare to those of other psychological fields, researchers found the frequency of troublesome academic procrastination among undergraduate students is 70\% - 95\% [7]. According to Temporal Motivation Theory [7], procrastination reflects personality traits which promote disregard behavior, such as low self-regulation behavior, which also means that not being a procrastinator indicates some favorable characteristics such as high self-esteem and efficacy. The research of procrastination has somewhat limited in variables related to self-regulation [8]. The current study examines a personal characteristic variable: achievement goal orientation. 


\section{The current study}

Few studies have invested procrastination and its related factors in non-Western settings, let alone secondary school population. Several studies [2] has examined procrastination about all four achievement goal orientations criteria consist of the two $\cdot$ two achievement goal taxonomy, which was designed for undergraduate population. The current research employs a validated procrastination self-report scale to investigate its relationship with the achievement goal orientations framework. It's hypothesized that a negative correlation between futureorientation and students' procrastination level; and an inverse relationship between performance approach and mastery approach goal orientation with procrastination; And, finally, a positive relationship between mastery avoidance and performance avoidance goal orientations.

\section{Literature Review}

Some key factors have been suggested to correlate with college students' procrastination behaviors. Procrastination is frequently associate with negative actions among students, like low-quality works, overdue submission, test and social anxiety, and under-achievement. These behaviors could all lead to mental health damage, depression and anxiety [9,10,11,12]. Among all of the investigated variables which is in relation with academic procrastination self-efficacy, and self-esteem show to be the most trendy variables.. [13,7,14,15] The following section provides a literature review of some related variables.

\section{Future-Orientation and Procrastination}

Using an achievement goal framework, researchers have demonstrated the association between Future-Orientation and Procrastination among college students. Several studies have determined that during school students who are different in their learning purposes and motivations, will receive different emotional, cognitive outcomes [16,17,18]. Goal orientation a individual's tendency toward developing or validating one's capability to achieve their presetting goals [19]. The current study uses the definition conceptualized by [20]to interpret the term Goal orientation, which is derived into four types of goal orientation in a 2.2 achievement goal framework [2] - where an approach versus avoidance dimension and a mastery versus performance dimension. The performance-approach orientation describes students who motivated themselves to do better than their classmates; the performance-avoidance prompt describes students who try to stay away from bad performance relatively to other. And the mastery-approach orientation describes students who try to study what is available for them as much as possible and mastery-avoidance orientation catalog students who try to keep away from learning as much as possible.

Approach orientation is shown to be negatively correlated with procrastination. Although there are limited studies, conclude the relationship between procrastination and approach goal orientation, particularly the mastery-approach, the results do consistently with each other claiming a negative relationship between the two. Moller and Elliot [21] suggest that approach orientations (e.g., mastery-approach) are positively related to self-regulatory process, a variable that is negatively related to procrastination (discussed in the next section). It can be inferred that procrastination should be inversely related with the approach orientations, which can help to reduce the likelihood to engage in sentiment orientation, a factor that is positive related to procrastination $[22,15,23]$. Without investigating approach or avoidance orientation, most existing research shows a negative correlation between procrastination and mastery ori- 
entation [24,25], while McGregor \& Elliot for a null result [20]. The relationship between procrastination and mastery approach was further proved to be negatively related by Andrew J. H, 2007, by using the exact two by two achievement frame work on 176 undergraduates. As shown in researches, performance-approach orientation is not correlated with procrastination $[20,25]$, yet does in some other once[15].

Avoidance orientation is shown to be negatively correlated with procrastination. The results from [21] also suggests that there should be a positive relationship between avoidance goal orientation, especially master avoidance orientation since such kind of orientation will cause temporal fluctuation. By using the inter-correlation statistic analyzation between the two variables, Howell \& Watson [2] proves that mastery-avoidance goal orientation is positively correlated with procrastination. This result can be explained by Elliots and McGregor's [20] founding that the fear of failure is strongly related to mastery-avoidance goal orientation category . And researches do show that performance-avoidance orientation is positively correlated with procrastination.

\section{Other variables related to procrastination}

Different approaches to learning, like planned approach, un-planned approach, are also related to a student's procrastination tendency. Procrastination can be view as a failure in selfregulation of one's own performance [13]: procrastinator fails to control a large load of work under a stressful situation. This finding has been proved by another study claiming that students who have problems in academic self-regulation often have immense procrastination practice [27]. Wolters also examined the link between self-regulation study practice and procrastination actions and found it to be the "second strongest predictor" after self-efficacy [15]. To conclude, evidence suggests a lower level of self-regulating behaviors leads to higher level of procrastination behaviors.

Self-efficacy, what we believe about our self, would also provide students with motivations of working and, therefore, reduce their procrastination behavior. Students with high selfefficacy would more often approach their school works willingly since they see them feasible. Self-efficacy can a strong indicator of performance in a academic setting. It is about dependent associate with the task in question [28]. Many have studied the association between selfefficacy and procrastination, with results suggesting a positive relationship between the two variables $[29,7,15]$. Academic self-efficacy can determine student's academic performance significantly, some up to $11 \%$ [30]. And this effect can be observed among high school students as an increase or decrease in grade [26]. A positive correlation was found by Klassen [31] between academic self-efficacy and procrastination in a sample of native Canadian university students. A significant negative influence on academic procrastination was found on another group of Korean college students [32]. However, researchers also warn that selfefficacy measures need to be assigned into different domains that are closely corresponded, otherwise it loses the predictive power [6]. Robert also argues that self-efficacy cannot describe a person in all aspects and, therefore, would lost correlation with procrastination.

Another characteristic category that was often mentioned together with self-efficacy is selfesteem, the judgments of global self-worth [3]. Self-esteem also receives a considerable amount of attention from procrastination literature [20,25]. Procrastination is often used as a reason to explain low self-esteem: numerous studies have found an inverse relationship between the procrastination behavior and self-esteem [34]. Flett [34] proposes that people who have low self-esteem tend to engage in behaviors such as task delay or avoidance and often 
use excuses to explain poor-performance. Above all, considerable researches have investigated in the relationship between self-esteem and procrastination.

\section{Participants and procedure}

One hundred Chinese high school students (50 males, 50females; mean age $=16$, SD = 1.14) at a Beijing international school participated in this study. After having the prior knowledge of the research explained to them in class, they were voluntarily recruited from a Chinese Civilization class. Student participants were instructed to complete an online survey with total of 27 items, which took about 5 minutes to complete.

\section{Measurement}

Procrastination Assessment Scale - Students. The extent to which student procrastinate in six major academic areas (studying for exams, attendance tasks, keeping up with weekly reading assignments, term paper and school activities in general academic administrative tasks,) are self-reported. And the Procrastination Assessment Scale - Students assess the extent to which procrastination in the six areas become a problem to them [1]. Students respond to two five-point scales with endpoints labeled 1 (never procrastinate) and 5 (always procrastinate) for the common problem items and 1 (not at all a problem) and 5 (always a problem). Responses are summed across the 12 items, with higher scores indicating greater procrastination level. Previously, Howell et al reported have demonstrated a significant correlation between the procrastination behavior and PASS scores.

The Achievement Goal Questionnaire. There is a total of 12 items in the Achievement Goal Questionnaire [20] with every three items composing each of the four-achievement goal orientation in the two by two achievement goal taxonomy. By averaging the three trails, the scores for each goal orientation is calculated. Elliot and McGregor [35] reported evidence attesting the reliability of mastery-approach $(\mathrm{a}=.87)$, mastery-avoidance $(\mathrm{a}=.89$ ), performance-approach $(\mathrm{a}=.92)$ and performance-avoidance $(\mathrm{a}=.83)$ goal orientations.

\section{Procedure}

On a random class day, students were invited to complete the questionnaire package during a one-hour class period. No incentive for participation was offered. The Achievement Goal Questionnaire was completed first, followed by the PASS.

\section{Results}

\section{Detailed statistics measured}

Results were analyzed using SPSS for Windows, version 17. Detailed statistics are reported in Table 1. Among the procrastination and achievement goal variables, performance avoidance approach seems to be the most common $(\mathrm{M}=4.76$, $\mathrm{SD}=1.37)$ compare to master approach $(\mathrm{M}=4.68, \mathrm{SD}=1.54)$, Mastery Avoidance $(\mathrm{M}=4.58, \mathrm{SD}=1.65)$, and Performance Approach $(\mathrm{M}=3.89$, SD = 1.51). Among the Procrastination Assessment Scale variables, doing summative work shows to be the category where most students are procrastinated in or 
worries about $(\mathrm{M}=3.16, \mathrm{SD}=1.16)$ higher than studying for exam $(\mathrm{M}=3.10, \mathrm{SD}=1.16)$. Meeting with advisor scored the lowest $(\mathrm{M}=1.90, \mathrm{SD}=0.62)$.

\section{Inter-correlations among variables}

As shown on Table 2, scores on the PASS correlated negatively with the future orientation total mean score, as predicted. Additionally, PASS scores is positively correlated with performance-avoidance goal orientation. However, contradicting the hypothesis, Mastery Avoidance correlates with PASS scores positively, instead of negatively. As predicted, futureorientation is inversely related to exam revision.

Negative associations emerged between all goal orientation and doing summative work, exam revision, and keeping up reading. Except there is no relation between performanceavoidance and keeping up reading. And the other two PASS variables activity participation and meeting with advisor did not correlate with procrastination scores.

\section{Discussion}

Procrastination was negatively associated with both master-approach orientation and master-avoidance orientation. High school students who adopted the goal to learn knowledge possible or to avoid falling behind tended not to procrastinate. As suggested by the Temporal Motivation Theory [7], mastery-approach orientated students who has greater motivation tended not to procrastinate [35], which provides a more short-term award for studying and reduce the discontent generated by tiredness. However, the numerical evidence does not support the negative correlation between procrastination and master-avoidance orientation [21], since greater task aversion can lead to greater dissatisfaction. This divergence between theory and this experiment might be hinge upon the difference sample population which the experiment is conducted on. While college students in the U.S are the sample for Moller and Elliot, this experiment is conducted on high school students in Beijing. The negative relationship might cause by the motivation provided by the consequences when students failed to learn (e.g., domestic pressure, peer-pressure).

Results also reveal a positive association between performance-approach and performanceavoidance goal orientation and procrastination. Students who adopt the goal of performing better than their peers in the study tended not to procrastinate. This funding is in line with prior research $[15,25]$, where the tendency of procrastination is linked to the impact of task postponement. Specifically, intentional or unintentional delays may worry those performingorientated students (i.e., last-minute preparation is seen as not sufficient relatively to their peers). In contrast, performance-avoidance orientation students, who look to avoid performing poorly relative to others, is less affected by these consequences. Plus, they sometimes benign from delaying task (e.g., leaving work to the last-minute boots their efficiency), while the pressure of others doing better than them is negligible. Performance approach orientation, in general, have higher negative association compare to mastery approach and mastery avoidance. This is different from [2], where mastery approaches are shown to have a stronger association with procrastination. This divergence perhaps because of the difference in population. Whereas college students, a sample of Andrew and David, are more self-driven and less related with each other, high school students are more like a class, and their performance are often compared by instructor or parents. More significant peer-pressure cause high school students to more likely adopt future orientation in the performance branch. 
Table 1. Means and standard deviation for variables $(\mathrm{N}=141)$

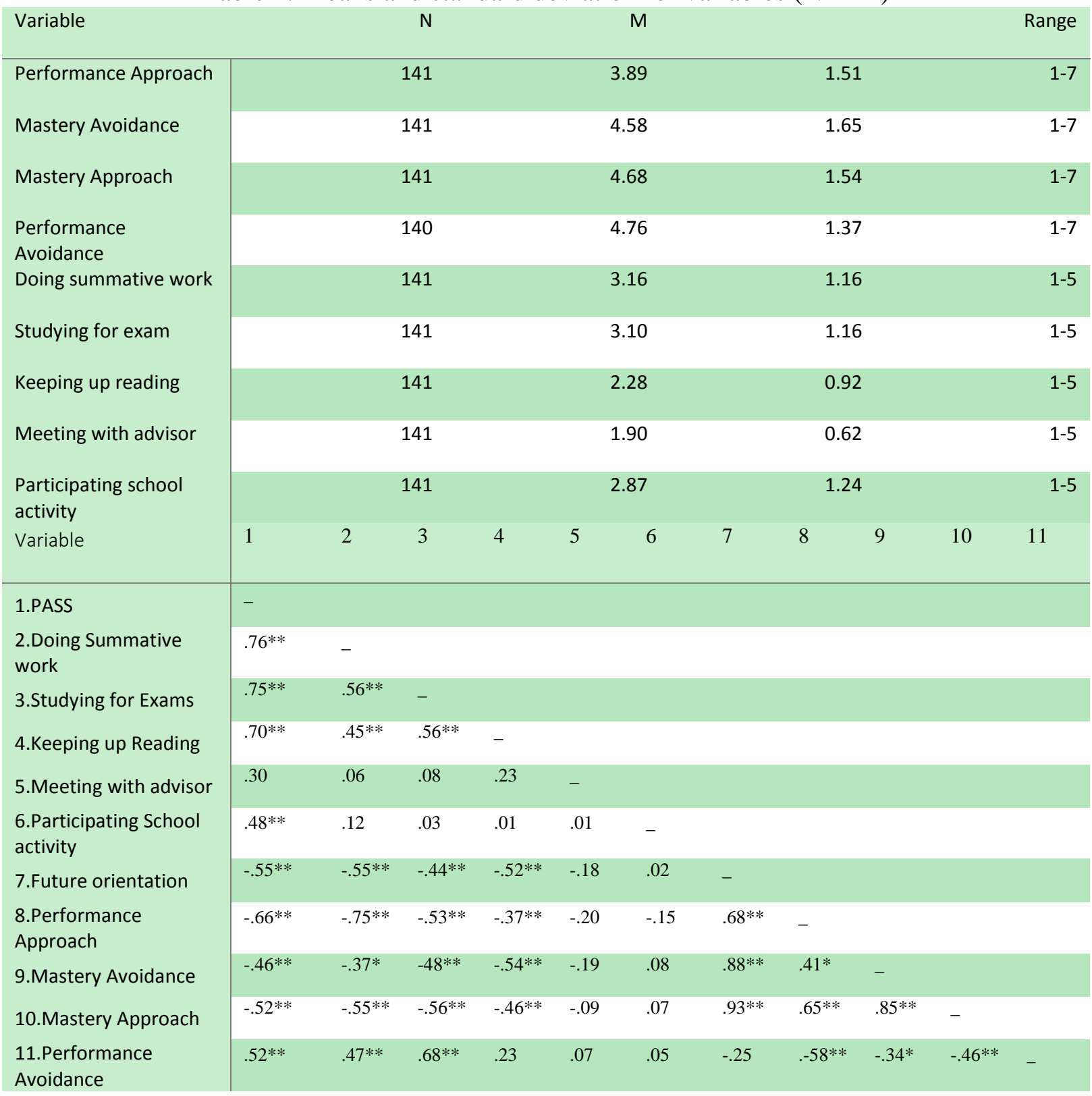

\section{Limitations and future directions}

The sample comprised grade 7 - 11, Bilingual (English and Chinese) high school students enrolled in an international school in Beijing. Thus, the result would be uncertain to generalize to more students in Beijing or college undergraduates in a different curriculum, age, or cultural background. Although we can draw a general relationship between achievement goal orientations and procrastination in the experiment, no direct causal relationship can be determined since other factors in student's learning process have not been taken into account. A limitation of this experiment concerns the reliability of self-report survey of PASS and goal orientation. Other factors like parents' behaviors (e.g., frequently checking student's work) 
could also be further explored in relation with student's procrastination behavior since they also play an important factor in high school student's life. Future research could also examine ways to regulate procrastination behaviors, which have a more significant practical use. For example, one way could be to determine the relationship between Cognitive learning strategy and procrastination in high school students, since the result of such experiment could then be applied to reduce the impact of the deleterious form of procrastination.

\section{Reference}

[1]Solomon, L. J., \& Rothblum, E. D. (1984). Academic procrastination: frequency and cognitive-behavioural correlates. Journal of Counseling Psychology, 31, 504-510.

[2] Andrew J. Howell, David C. Watson (2007). Procrastination: Associations with achievement goal orientation and learning strategies. Personality and Individual Differences, 43, 167178

[3] Bandura, A. (1993). Perceived self-efficacy in cognitive development and functioning. Educational Psychologist, 28, 117-148.

[4]Moon, S. M., \& Illingworth, A. J. (2005). Exploring the dynamic nature of procrastination: A latent growth curve analysis of academic procrastination. Personality and Individual Differences, 38(2), 297-309. doi:10.1016/j.paid.2004.04.009

[5] Chu, A. H. C., \& Choi, J. N. (2005). Rethinking procrastination: positive effects of “active" procrastination behavior on attitudes and performance. Journal of Social Psychology, 145(3), 245-264.

[6] Robert M. K, Lindsey L. K, \& Sukaina R(2007). Academic procrastination of undergraduates: Low self-efficacy to self-regulate predicts higher levels of procrastination. Contemporary Educational Psychology 33, 915-931.

[7] Steel, P. (2007). The nature of procrastination: A meta-analytic and theoretical review of quintessential self- regulatory failure. Psychological Bulletin, 133, 65-94.

[8] Schouwenburg, H. C. (2004). Procrastination in academic settings: general introduction. In H. C. Schouwenburg, C. H. Lay, T. A. Pychyl, \& J. R. Ferrari (Eds.), Counseling the procrastinator in academic settings (pp. 3-17). Washington: American Psychological Association.

[9] Dewitte, S., \& Schouwenburg, H. C. (2002). Procrastination, temptations, and incentives: The struggle between the present and the future in procrastinators and the punctual. European Journal of Personality, 16, 469-489.

[10] Ferrari, J. R. (2000). Procrastination and attention: Factor analysis of attention deficit, boredomness, intelligence, self-esteem, and task delay frequencies. Journal of Social Behavior and Personality, 15, 185-196.

[11] Fritzsche, B. A., Young, B. R., \& Hickson, K. C. (2003). Individual differences in academic procrastination tendency and writing success. Personality and Individual Differences, 35, 1549-1557. 
[12]Lee, E. (2005). The relationship of motivation and flow experience to academic procrastination in university students. The Journal of Genetic Psychology, 166, 5-14.

[13]Ferrari, J. R. (2001). Procrastination as self-regulation failure of performance: Effects of cognitive load, self- awareness, and time limits on 'working best under pressure.'. European Journal of Personality, 15, 391-406.

[14] Tuckman, B. W. (1991). The development and concurrent validity of the procrastination scale. Educational and Psychological Measurement, 51, 473-480.

[15] Wolters, C. A. (2003). Understanding procrastination from a self-regulated learning perspective. Journal of Educational Psychology, 95, 179-187.

[16] Covington, M. V. (2000). Goal theory, motivation, and school achievement: an integrative review. Annual Review of Psychology, 51, 171-200.

[17] Elliot, A. J. (2005). A conceptual history of the achievement goal construct. In A. J. Elliot \& C. S. Dweck (Eds.), Handbook of competence motivation (pp. 52-72). New York: Guildford Press.

[18] Pintrich, R. R. (2000b). The role of goal orientation in self-regulated learning. In M. Boekaerts, P. R. Pintrich, \& M. Zeidner (Eds.), Handbook of self-regulation (pp. 451-502). New York: Academic Press.

[19] VandeWalle, D. (1997), Development and validation of a work domain goal orientation instrument, Educational and Psychological Measurement, 8, 995-1015.

[20]Elliot, A. J., \& McGregor, H. A. (2001). A 2 - 2 achievement goal framework. Journal of Personality and Social Psychology, 80, 501-519.

[21] Moller, A. C., \& Elliot, A. J. (2007). The $2 \cdot 2$ achievement goal framework: an overview of empirical research. Progress in Educational Psychology Research.

[22] Chen, B. -B., \& Chang, L. (2012). Bitter struggle for survival: Evolved bitterness embodiment of survival motivation. Journal of Experimental Social Psychology, 48, 579-582.

[23] Kruger, D. J., Reischl, T., \& Zimmerman, M. A. (2008). Time perspective as a mechanism for functional developmental adaptation. Journal of Social, Evolutionary, and Cultural Psychology, 2, 1-22.

[24] Scher, S. J., \& Osterman, N. M. (2002). Procrastination, conscientiousness, anxiety, and goals: exploring the measurement and correlates of procrastination among school-aged children. Psychology in the Schools, 39, 385-398.

[25] Wolters, C. A. (2004). Advancing achievement goal theory: using goal structures and goal orientations to predict students' motivation, cognition, and achievement. Journal of Educational Psychology, 96, 236-250.

[26] Elias, S. M., \& MacDonald, S. (2007). Using past performance, proxy efficacy, and academic self-efficacy to predict college performance. Journal of Applied Social Psychology, 37(11), 2518-2531. doi:10.1111/jasp.2007.37.issue-11.

[27]Senecal, C., Koestner, R., \& Vallerand, R.J. (1995). Self-regulation and academic pro- 
crastination. Journal of Social Psychology, 135, 607-619.

[28] Pajares, F. (1996). Self-efficacy beliefs in academic settings. Review of Educational Research, 66, 543-578.

[29]Pajares, F. (1996). Self-efficacy beliefs in academic settings. Review of Educational Research, 66, 543-578.

[30] Multon, K. D., Brown, S. D., \& Lent, R. W. (1991). Relation of self-efficacy beliefs to academic outcomes: A meta-analytic investigation. Journal of Counseling Psychology, 38(1), 30-38. doi:10.1037/0022-0167.38.1.30.

[31] Klassen, R. M. (2007). Using predictions to learn about the self-efficacy of early adolescents with and without learning disabilities. Contemporary Educational Psychology, 32, 173187.

[32] Seo, E. H. (2008). Self-efficacy as a mediator in the relationship between self-oriented perfectionism and academic procras- tination. Social Behavior and Personality, 36(6), 753764. doi:10.2224/sbp.2008.36.6.753.

[33] Beck, B. L., Koons, S. R., \& Milgrim, D. L. (2000). Correlates and consequences of behavioral procrastination: The effects of academic procrastination, self-consciousness, selfesteem, and self-handicapping. Journal of Social Behavior and Personality, 15, 3-13.

[34]Flett, G. L., Blankstein, K. R., \& Martin, T. R. (199525). Procrastination, negative selfevaluation, and stress in depression and anxiety. In J. R. Ferrari, J. L. Johnson, \& \& W. G. McCown (Eds.), Procrastination and task avoidance: Theory, research, and treatment (pp. 137-167). New York: Plenum Press.

[35] Elliot, A. J., McGregor, H. A., \& Gable, S. (1999). Achievement goals, study strategies, and exam performance. Journal of Educational Psychology, 91, 549-563.

[36] Elliot, A. J., \& Harackiewicz, J. M. (1996). Approach and avoidance achievement goals and intrinsic motivation: a mediational analysis. Journal of Personality and Social Psychology, 70, 461-475. 